\title{
O QUE É ISSO? PARA QUE SERVE? QUEM SÃO VOCÊS? O QUE FAZEM? UMA EXPERIÊNCIA DE ARQUEOLOGIA PÚBLICA EM PARANÃ - TO*
}

\author{
Leilane P. Lima** \\ Gilberto da Silva Francisco***
}

\begin{abstract}
Resumo: O objetivo deste artigo é comentar a noção de parceria no debate sobre a Arqueologia Pública, especificamente na dinâmica escolar. A compreensão do papel da Arqueologia nesse contexto terá como ponto de partida a experiência dos autores como professores-arqueólogos na Semana de Arqueologia, realizada no município de Paranã - estado do Tocantins, evento relacionado a atividade de pesquisas arqueológicas numa região de impacto ambiental, dada a construção de um empreendimento hidrelétrico no médio vale do rio Tocantins.
\end{abstract}

Palavras-chave: Identidade, Arqueologia Pública, Educação Patrimonial, Patrimônio, Parceria.

“(...) Fiquei pensando, e comecei a descrever Tudo, tudo de valor que o Brasil me deu 0 céu azul, um Pão-de-açúcar sem farelo Um pano verde e amarelo, tudo isso é meu! Tem feriado que pra mim vale fortuna, A Retirada de Laguna, vale um cabedal Tem Pernambuco, tem São Paulo, tem Bahia Um conjunto de harmonia que não tem rival."

(Trecho da música Recenseamento, de Assis Valente)
(*) Este trabalho foi desenvolvido como parte integrante do "Programa de Pesquisa e Resgate do Patrimônio Arqueológico, Histórico e Cultural do AHE Peixe-Angical, estado do Tocantins", desenvolvido desde 1998 pela empresa DOCUMENTO Antropologia e Arqueologia. A coordenação do Programa é dos Profs. Drs. Erika M. Robrahn-González e Paulo De Blasis, contando com o apoio institucional do Núcleo
Por conta do recenseamento de 1940, conta Carmem Miranda (a intérprete da música de Assis Valente), que um censor bastante autoritário bate à porta de um lar humilde e começa a esmiuçar a vida de uma brasileira, que, em desconforto, prefere lembrar das coisas "de valor que o [seu] Brasil [lhe] deu". Assim, frente à pergunta: - quem é você? (bastante peculiar dos objetivos de um censo), além de falar de si mesma, como indivíduo, também responde a partir de sua inserção num grupo, numa generalidade, na sua nação. 0 cadinho de referências é varia-

de Estudos Estratégicos/ UNICAMP e da Fundação Cultural de Jacarey. A obra é de responsabilidade da empresa ENERPEIXE S/A.

$(* *)$ Museu de Arqueologia e Etnologia da Universidade de São Paulo Leilaneplima2004@yahoo.com.br $(* * *)$ Museu de Arqueologia e Etnologia da Universidade de São Paulo gisifran@yahoo.com.br 
do: riquezas naturais, símbolos nacionais, feriados (a memória de alguns eventos históricos selecionados), e a própria idéia de harmonia interestadual (clara idealização: é só lembrarmos que pouco antes de 1940, a presença do pernambucano João Alberto como interventor de São Paulo (1930-1931), nomeado por Getúlio Vargas, causou imenso desconforto na elite paulista, havendo inclusive um surto preconceituoso contra nordestinos).

Apesar de ser uma música datada (por exemplo, o IBGE [Instituto Brasileiro de Geografia e Estatística] procura não empreender um censo tão autoritário), algumas das referências peculiares desse "samba exaltação" poderiam vir à mente de qualquer um, quando perguntado "- o que o define como brasileiro?". Assim, quais são as coisas que consideramos realmente importantes, aquelas que caracterizam parte do que somos, e nossa inserção em certo grupo? É certo que essas referências são inúmeras, e que a constituição desse grupo de coisas "que consideramos nossas" não tem uma constituição natural; ou seja, existem processos ( por vezes de longa duração, retomando termos braudelianos (Braudel, 1986), ou então de recentíssima criação, "tradições inventadas", conforme Eric Hobsbawn, 1997) constituídos a partir de interesses múltiplos (determinados anseios de grupos sociais, autoconsciência grupal, extensão do projeto de um grupo a outro, através de práticas de dominação etc.). Ainda, essa sensibilidade quase "natural" das pessoas frente a um símbolo, ação etc. com que se identifica, forjase, geralmente, num processo longo de educação, que está também ligado à ação escolar (ensino público ou privado), mas não somente a ele: a educação é um processo bastante amplo, sendo agregado em situações familiares, acesso às informações através de mídias diversas, dentre outros. Nesse quadro, qual o papel da Arqueologia?

É importante saber, de início, que a idéia que se tem sobre a Arqueologia, no senso comum, caminha entre um desconhecimento quase absoluto da disciplina (do que trata a Arqueologia? Nunca ouvi falar!...) e uma vi- são idealizada do arqueólogo (Indiana J ones, Tomb Raider etc.), bem como do objeto arqueológico (algo como uma relíquia, valioso materialmente e por suas características históricas). Tratar de Arqueologia fora de alguns centros especializados geralmente parte de uma situação de amplo desconhecimento do público leigo, entretanto, há um certo interesse. Por ocasião da comemoração dos 500 anos do Brasil, a grande exposição no Ibirapuera (Mostra do Redescobrimento. Brasil+500) apresentava, no conjunto das inúmeras peças, a famosa carta de Pero Vaz de Caminha, e a procura por tal documento era especialmente grande. 0 acesso ao seu conteúdo é simples (qualquer busca na Internet, por exemplo, satisfaria tal necessidade) $;{ }^{1}$ mas era imperativo para muitos ver com os próprios olhos, mesmo que a grafia de tal carta não fosse legível para a maioria (ver figura 1), sendo necessário competência para leitura paleográfica, o que a maioria dos visitantes não possuía. o que mais interessava era ver a carta em si, a carta-objeto; e, para sanar o problema de conteúdo, a organização da exposição criou uma cabine com recitação da carta feita pelo ator Paulo Autran. Esse pequeno exemplo indica a importância do fetiche que pode incidir sobre o objeto material.

Os materiais arqueológicos apresentam uma certa eloqüência, que contribui grandemente para um interesse inicial. Ou seja, parece, ao olho leigo, que o objeto material é auto-explicativo; assim, se os problemas de interpretação no seio da Arqueologia são complexos e variados, a dimensão física do objeto convida o leigo, e esse interesse pode tornar-se uma posterior reflexão mais aprofundada (as múltiplas ações relaciona-

(1) Em uma rápida busca na Internet, no site www.google.com.br (em fevereiro de 2006), a entrada "Carta" e "Caminha" proporcionou a indicação de 342.000 páginas disponíveis na Web, 321.000 em português e 198.000 páginas brasileiras. Levandose em conta que nem todas apresentam o texto parcial ou integralmente, o número, mesmo com isso, é bastante expressivo. Quanto à busca de imagens visuais, no mesmo site, disponibilizavam-se 175 páginas 


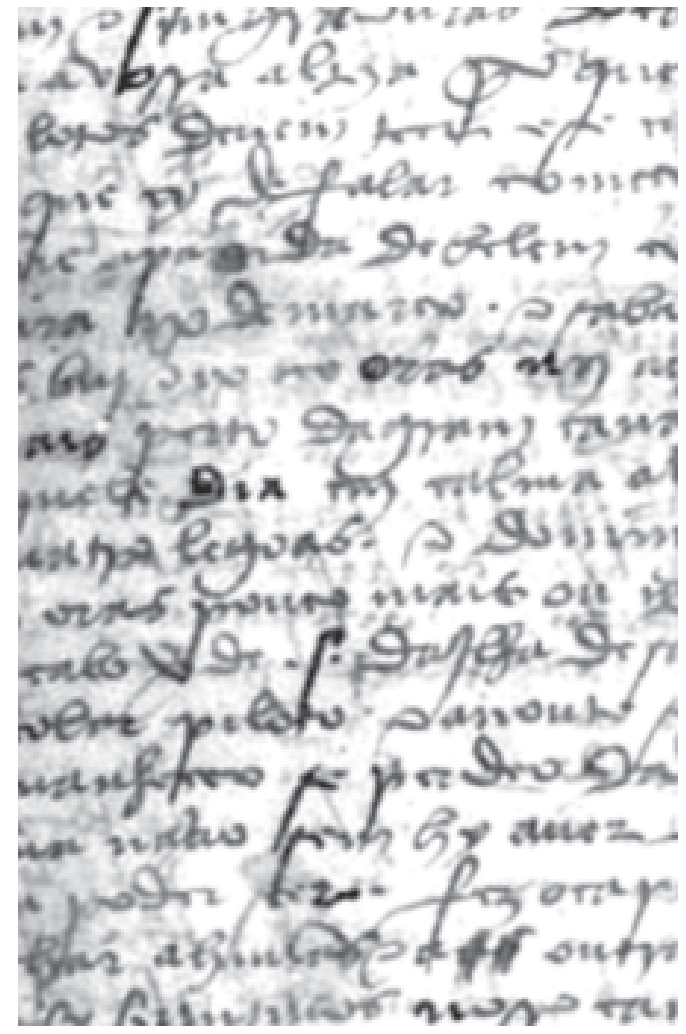

Fig. 1. Detalhe da Carta de Pero Vaz de Caminha, 1500. Torre do Tombo, Portugal.

das à Arqueologia Pública são essenciais nesse sentido, pois podem contribuir para um abandono da fetichização...).

Como visto, contra um desconhecimento grande sobre a Arqueologia (a disciplina e a prática), há uma atenção preliminar do público leigo, interesse de que o arqueólogo voltado às práticas públicas deve lançar mão. Porém, esse é apenas um primeiro passo, e não se deve converter esse interesse em toda idéia de Arqueologia Pública; já que muitas vezes esse cenário estrutura-se em torno de uma Arqueologia fantástica, o que destoa freqüentemente das propostas e materiais apresentados: quando as expectativas residem em materiais de metais preciosos, monumentais, e se apresentam apenas poucos fragmentos de cerâmica, ou líticos pouco trabalhados.

\section{Arqueologia Pública e patrimônio: al- guns pressupostos teóricos}

Entre as inúmeras transformações que ocorreram relacionadas à Arqueologia praticada no Brasil, especialmente nas últimas décadas, podemos citar um maior engajamento político por parte dos arqueólogos. Nas palavras de Funari (2005: 5)

\section{(...) os aspectos públicos, de interação} e ação conjunta com as comunidades, tanto locais, como regionais, nacionais e transnacionais, passaram a representar parcela crescente e cada vez mais significativa da prática e teoria arqueológica.

Somado a esse engajamento político, a aprovação das leis brasileiras de proteção do patrimônio arqueológico, ${ }^{2}$ no âmbito federal, estadual e municipal, ${ }^{3}$ contribuiu para a multiplicação dos trabalhos de campo ligados a licenciamentos ambientais (Funari, 2005: 6); sendo seguidas essas atividades, em alguns casos, por ações de cunho público. A Arqueo-

(2) As publicações sobre o tema Arqueologia Pública e relacionadas utilizam o termo patrimônio com conotações variadas, o que deve ser brevemente esclarecido. Há, então, a utilização de termos como "patrimônio público", "patrimônio cultural" e "patrimônio arqueológico", ou mesmo o termo patrimônio isolado. Os complementos público e cultural, por vezes guardam certa equivalência, mas o primeiro é mais abrangente; ou seja, o patrimônio público não se restringe ao patrimônio cultural, é mais amplo. O mais específico deles é o termo "patrimônio arqueológico", que se insere nos outros. Assim, o patrimônio arqueológico é também patrimônio cultural e público.

(3) Destacam-se, nesse sentido: 1) A Lei no 3.924, de 26/07/1961, que proíbe a destruição ou mutilação para qualquer fim, da totalidade ou parte das jazidas arqueológicas, o que é considerado crime contra o patrimônio nacional; 2) A Constituição Federal de 1988 (artigo 225, parágrafo IV), que considera os sítios arqueológicos como patrimônio cultural brasileiro, garantindo sua guarda e proteção, de acordo com o que estabelce o artigo 216; 3) A Portaria SPHAN/MinC 07, de 01/12/1988,que normatiza e legaliza as ações de intervenção junto ao patrimônio arqueológico nacional; 4) Portaria IPHAN/MinC no 230 , de 17/12/2002, que define o escopo dos estudos arqueológicos a serem desenvolvidos nas diferentes fases de licenceamento ambiental (Fonte: Material oferecido por Documento Antropologia e Arqueologia). 
logia Pública, segundo Ascherson (1999, Apud Funari, Oliveira \& Tamanini, 2005: 106),

é compreendida (...) como todos os aspectos públicos da Arqueologia, incluindo tópicos como políticas arqueológicas, educação, política, religião, etnicidade, envolvimento público em Arqueologia.

A Arqueologia Pública tende, geralmente, a estabelecer diálogos com áreas paralelas como a Museologia, de onde surgem questões estritamente ligadas ao patrimônio e conscientização do leigo. Podemos definir patrimônio como o conjunto dos bens identificados pelo homem, a partir de suas relações com outros homens e com o meio ambiente e a própria interpretação que ele faz dessas relações (Bruno, 2002: 89, Apud Bessegato, 2004: 33). Além disso, conforme Oosterbeek (2005: 97), o conceito de patrimônio cultural nos remete ao de propriedade, algo a que atribuímos um valor e estabelecemos uma relação de apropriação.

Os bens culturais, num sentido amplo, são os testemunhos da cultura humana e do meio no qual construímos nossa identidade individual e (ou) coletiva através da memória. Caldeira (2006: s. p.) revela que desde os tempos mais remotos existe a preocupação em preservar os bens culturais. Especialmente no período pós 2a Guerra Mundial, vários setores das sociedades ocidentais passaram a enfatizar a importância dos bens culturais e a sua proteção tornou-se um direito e um dever de todos (Idem). Assim, várias associações foram criadas visando discutir políticas de defesa e conservação preventiva de bens culturais. Elas promoveram a criação regulamentar de diversas estratégias de restauro, conservação e proteção do patrimônio cultural. ${ }^{4}$

(4) Destacam-se, dessa forma, esforços como a Carta de Atenas (1931), Carta de Veneza (1964) e Carta Italiana (1987), que visavam um debate e organização internacional de um corpus regulamentar para a área de conservação e restauro (ver Caldeira, op. cit.).
Essa correspondência entre a idéia de patrimônio (seleção) e conservação (permanência) é presente inclusive na acepção de dicionário: segundo o Dicionário Houaiss da língua portuguesa, patrimônio define-se, também, como

bem ou conjunto de bens naturais ou culturais de importância reconhecida num determinado lugar, região, país ou mesmo para a humanidade, que passa $(m)$ por um processo de tombamento para que seja $(\mathrm{m})$ protegido(s) e preservado(s).

0 ato de identificar e selecionar o que é relevante para a memória de uma comunidade local, de um estado ou de um país gera problemas. Por exemplo, a instituição museu, enquanto lugar de preservação e gestão de vários desses bens culturais, muitas vezes está exposto ao jogo de interesses políticos. Assim,

Devemos considerar a existência de uma intenção inicial que se traduz em "razão para preservar", a qual muitas vezes se configura na criação de um espaço-museu. (...) Quando o Museu é idealizado de acordo com interesses ideológicos pela classe que ocupa o poder e nele procura manter-se, a instituição fatalmente funcionará como símbolo de força. (Almeida, 2005: 91)

E é nesse contexto que a Arqueologia Pública pode exercer um papel importante nos processos de resgate da memória, reconhecimento e valorização do patrimônio, pois a cultura material, ou seja, o que poderá tornar-se patrimônio arqueológico de uma determinada comunidade, pode ser tomada como elemento de memória que permite a contribuição na construção de uma identidade local/regional. Nas palavras de Bruno (1996, Apud Almeida 2005: 67), "os indicadores/vestígios das sociedades que correspondem ao interesse de estudo da Cultura Material são, também, elementos da herança patrimonial, tratados e comunicados pela Museologia". 
A Arqueologia busca compreender as sociedades humanas através da cultura material, e é a partir do resgate desses objetos pretéritos para o presente que 0 Museu recebe a atribuição de preservá-los dando-Ihes um novo significado (Almeida, 2005: 95). Em outras palavras, cabe à Arqueologia e à Museologia a transmissão do valor público do patrimônio arqueológico. Entretanto, vale dizer, uma Arqueologia e Museologia como vocações públicas; ou seja, buscando intensos diálogos (numa acepção ampla do termo) com as comunidades envolvidas nos processos liderados por essas áreas. Neste ponto, reforça-se a importância da educação patrimonial, por exemplo, no seio escolar. Isso, dado o papel agregador, socialmente falando, que as escolas têm: são espaços de ampla e variada circulação (alunos, professores e outros funcionários, pais, palestrantes etc.), havendo também a organização e experiência de alguns grupos como grêmios estudantis, associação de pais e mestres, entre outros.

As atividades relacionadas à ação de Arqueologia Pública no espaço escolar são geralmente resultado de projetos de implantação de grandes construções, e, dado o grande impacto ambiental, é, nessas regiões que ocorrem eventos educativos ligados à conscientização quanto ao patrimônio arqueológico. Segundo Bessegato (2004: 34)

(...) cabe à Educação Patrimonial ser uma atividade paralela, mas, ao mesmo tempo autônoma e interligada aos Projetos de Salvamento Arqueológico, efetuados na região atingida pelo empreendimento destas Empresas ou Companhia de energia hidrelétrica.

Mas, especialmente quando tratamos da relação entre Arqueologia e educação, deparamo-nos com algumas questões peculiares: por ser um tema que não é tratado diretamente em sala de aula (quando muito, um livro didático apresenta a pré-história do Brasil, ou monumentos gregos e romanos, de forma ilustrativa e sem reflexões propostas a partir deles). ${ }^{5}$

Nesse contexto, torna-se bastante importante a interação entre Arqueologia, educação patrimonial e musealização. Segundo Bessegato e Milder (2005: 85), "a temática do patrimônio é hoje uma das mais prolíferas e profícuas da nossa contemporaneidade, e por isso mesmo, essencial para levarmos o patrimônio para as salas de aula". Na mesma medida, a Museologia ganha força, sendo o museu deixado de ser tratado apenas como guardião móvel, para ser visto como meio de transmissão do patrimônio. Nas palavras de Almeida (2005: 40)

Se a comunidade que vive num espaço/território tem oportunidade de reconhecer seu passado enquanto herança e vislumbrar sua vivência social e histórica nas transformações infringidas ao meio ambiente, seja ele rural ou urbano, a questão da eleição sobre o que seria significativo ou não, em termos de preservação da memória e patrimônio, ou seja, a escolha daquilo que se pretende deixar para as novas gerações, penetra automaticamente no campo das ciências dos museus. Não se pode falar de identidade sem tratar dos processos de musealização.

Essas ações educativas não devem apenas oferecer um discurso pronto aos alu-

(5) As escolas brasileiras têm como obrigação criar planos pedagógicos que seguem orientações gerais, mas também respondem às realidades locais do público aprendizando, conforme algumas tendências mais ou menos recentes sobre pedagogia. A questão é que as matérias clássicas como História, Matemática, Geografia, Português, entre outras, são discutidas nos vários níveis (municipal, estadual e federal), e existe já uma experiência grande (teórica e prática) na execução das ações curriculares com relação a elas. No caso da Arqueologia na escola, a situação é bastante diferente. Como visto, a ampliação de um interesse de comunicação entre especialistas e público leigo é relativamente recente, e as práticas pedagógicas com relação ao ensino sobre Arqueologia ainda estão sendo discutidas, em estágio inicial. 
nos, faz-se necessário que os professoresarqueólogos, na senda de uma "pedagogia arqueológica", ${ }^{6}$ tenham em vista também a experiência do aprendizando. Assim, 0 papel do professor-arqueólogo é o de facilitador. Nas palavras de Bessegatto (2004: 30), "o professor tem a função de ajudar 0 aluno a se organizar, sensibilizando-o de forma que seus sentimentos possam ser expressos". Assim, a conscientização sobre o patrimônio arqueológico é, muitas vezes, tarefa de grande dificuldade; mas não apenas por causa desse conhecimento frágil e fragmentário, ${ }^{7}$ mas também, em vário casos, por um descompasso de linguagem entre o professor-arqueólogo e o público leigo. Para sanar tal problema não é necessário tornarse simplista nas explicações e propostas, mas trazer o outro, inseri-lo nas questões arqueológicas, às vezes abrindo mão de termos complicados: a saída pode ser lidar com conteúdos com os quais eles já têm alguma experiência.

\section{Uma Semana de Arqueologia em Paranã - Tocantins}

As pesquisas arqueológicas na região de Paranã ${ }^{8}$ inserem-se num quadro regional mais amplo (AHE [Aproveitamento Hidrelétrico] Peixe Angical), relacionadas às atividades de salvamento arqueológico, precedente à obra de construção de um gran-

(6) O termo "pedagogia arqueológica" pode parecer estranho e mesmo equivocado. Entretanto, existem esforços, ainda bastante iniciais, que indicam para uma proposta com fins educativos, baseando-se, inclusive, em literatura peculiar da discussão pedagógica. Não se trata, assim, de um corpus sistemático ou organizado de procedimentos, mas de algo que é perceptível, projeta-se em discussões recentes (Ver Bessegato, 2004 e Bessegato \& Milder, 2005).

(7) Um dos autores deste artigo, por exemplo, ao comentar com pessoas de níveis de escolaridade di- de reservatório hidráulico, em parte do curso do Rio Tocantins e do Rio Paranã (ver fig. 2). Além de Paranã, os municípios de Peixe, São Salvador e Palmeirópolis estão inseridos na zona de intervenção (e, portanto, de pesquisas arqueológicas precedentes). Nestes municípios haviam sido igualmente ministradas "Semanas de Arqueologia", sendo em Paraná, tratada no presente artigo, a última delas.

Essa Semana de Arqueologia ocorreu de 07 a 12 de novembro de 2005, e a maior parte dos eventos (palestras e atividades relacionadas) circunscreveu-se às quatro escolas públicas existentes na cidade: E. M. Floracy Bonfim Pereira de Araújo; E. E. Euclides Bezerra Gerais; C. E. Des. Virgílio de Melo Franco; E. M. Soldadinho de Jesus. As atividades envolveram mais de 5.000 alunos inscritos nas escolas.

O público era bastante variado, composto por alunos desde o ensino fundamental até adultos em situação de alfabetização; e de diferentes grupos sociais. Dessa forma, não poderia haver, por parte do palestrante, uma entonação única, mecânica, dada a variedade dos interlocutores.

O conteúdo das aulas era bastante amplo: uma introdução à Arqueologia, suas divisões (Arqueologia histórica e pré-histórica), suas fontes etc.; temas apresentados tanto de forma generalista, como específica (retomando as pesquisas arque-

ferentes (ensino básico e pós-graduação) que estuda Arqueologia, foi questionado da seguinte forma: "- você estuda para cavar chão?", e também, "-vocÊ ganha para fazer isso?".

(8) Alguns dados sobre a população de Paraná, segundo o IBGE, a partir do site www.ibge.gov.br e também a seção IBGE - Cidade@: A população estimada é de 10.071 pessoas (número de 01.07.2005). As matrículas executadas no ano de 2004 foram as seguintes: Ensino fundamental, 2.595 pessoas e Ensino médio, 224 pessoas. 


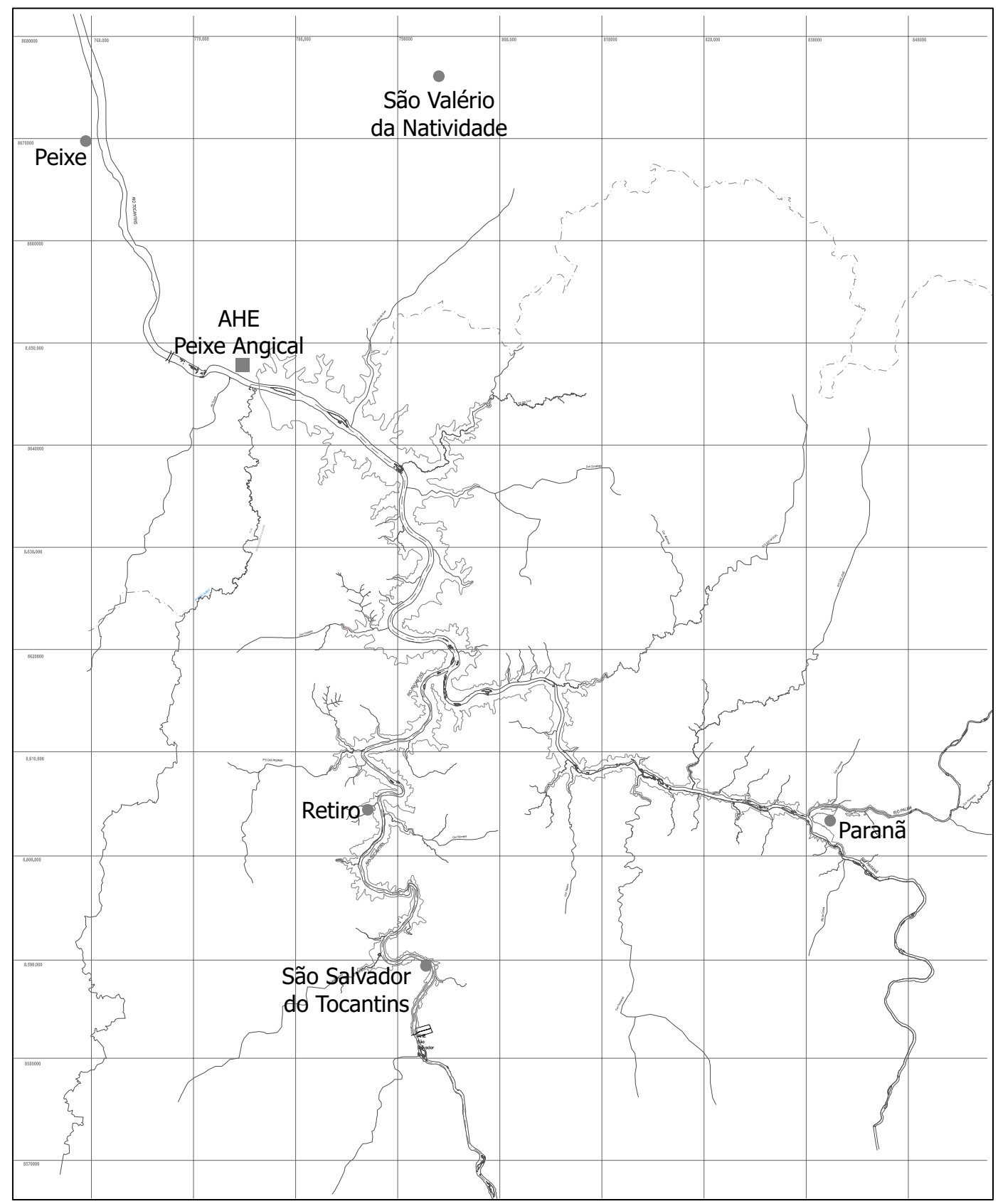

Fig. 2. Mapa o reservatório do AHE Peixe Angical.

ológicas da própria região). A estrutura básica do conteúdo ministrado era o seguinte:
- Primeiro dia - Introdução: O que é Arqueologia?; Arqueologia pré-histórica; A arte rupestre; ZooArqueologia; 
Arqueologia da morte; Arqueologia histórica.

- Segundo dia - O trabalho do arqueólogo: As escavações; Estudos de laboratório; Quando foi? (as datações); Arqueologia Pública.

- Terceiro dia - O patrimônio arqueológico do AHE Peixe Angical. Objetivos do projeto e dados gerais: Como se dá a pesquisa arqueológica na região; Um pouco da pré-história do Tocantins; A Era da diversificação: grupos caçadores-coletores mais recentes (9000 a 3000 anos); Sociedades cultivadoras (3000 a 1500 anos); Agricultores de grandes aldeias (1300 anos até a época atual).

- Quarto dia - História: Patrimônio histórico e cultural. Como se dá a pesquisa; A história do Tocantins... Nossa História (séc. XVIII-XX).

- Quinto dia - Patrimônio histórico edificado: Técnicas construtivas; Construções rurais; Construções urbanas; Conjuntos arquitetônicos.

Freqüentemente, o reconhecimento imediato acontecia quando tratadas as referências de Arqueologia histórica, sobretudo no tocante à arquitetura da cidade. Ao comentarmos aspectos da arquitetura local, mos- trando a imagem da Igreja da Matriz (ver fig. 3), tal situação era amplamente observada. Ainda, não era difícil encontrar quem reconhecesse a própria casa, de parentes ou vizinhos dentre as imagens apresentadas. Nesse sentido, havia intensas trocas de informações, por exemplo, muitos dos aprendizandos conheciam bem algumas das técnicas construtivas tratadas, como as casas de palha de Buriti, de adobe etc. Numa dessas aulas, um aluno chegou a explicar com detalhes, a todos, como se construía uma casa de pau a pique.

Entretanto, essa identificação não se restringiu apenas às referências de Arqueologia histórica. Por exemplo, comentar algumas técnicas da produção ceramista de populações indígenas antigas também ensejava lapsos de comunicação entre tempos bastante remotos (técnicas bastante antigas e ainda utilizadas recentemente).

Tal conteúdo, previamente estipulado, não era extremamente fixo, e o retorno do público aprendizando poderia propor diferentes encaminhamentos. Por exemplo, a algumas questões muito específicas da Arqueologia, como a estratigrafia, abriu-se um diálogo sobre o passar do tempo, as intempéries, a ação do homem e sua interferência sobre o solo. Ainda, contra um juízo simplista sobre a indústria lítica, a própria variedade de formas e usos do talhes que qualquer um

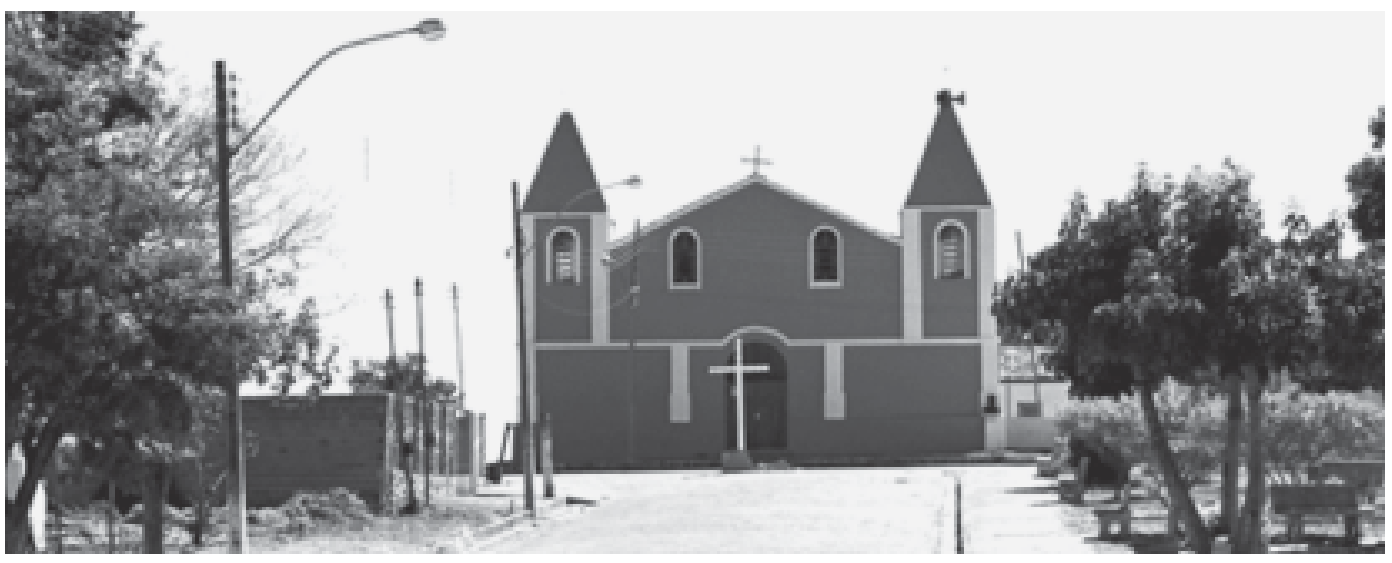

Fig. 3. Vista panorâmica da Igreja da Matriz, Paranã. 
tinha em casa, serviu como parâmetro comparativo.

A duração das aulas introdutórias era de aproximadamente quarenta e cinco minutos, dependendo da interação entre os professores-arqueólogos e público escolar (incluindo professores e outros funcionários da escola, que também participavam); e, após isso, eram empreendidas outras atividades que visavam compreender qual o impacto do que foi discutido antes. Claramente, dadas as variações etárias, as atividades eram pensadas levando em conta esses recortes: os mais jovens poderiam criar desenhos baseados na sua experiência (ver fig. 4), e, aos maiores, era proposta a criação de redações, poesias, repentes etc. Nesse caso específico, interessante foi o fato do distanciamento na questão da temporalidade, pois, numa dessas atividades, quando deveriam preencher a frase "para mim, a Arqueologia é...", as lacunas foram completadas repetitivamente com termos como passado, velho, antigo/antiguidade, antepassado, pré-história/história (numa acepção passadista), ruínas, mortos/ morte. Entretanto, a interação passado-presente (que está no cerne da questão patrimonial) e que buscávamos em vários momentos resgatar, também foi notada; é certo, por uma parte menos expressiva dos aprendizandos. Uma das atividades recebeu atenção especial das crianças, jovens e, ao

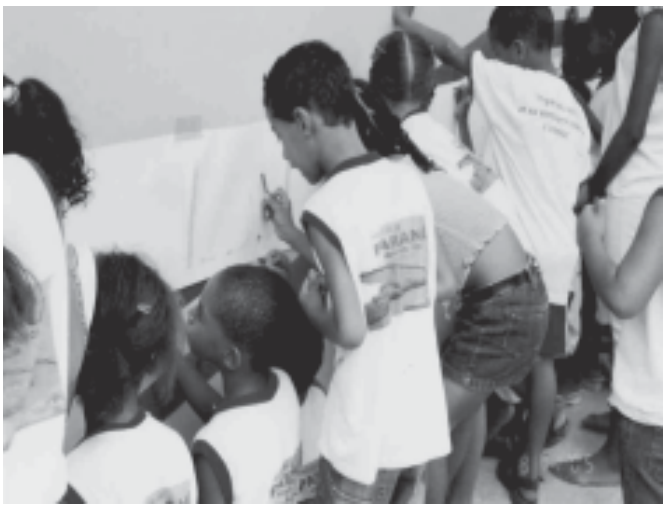

Fig. 4. Alunos da $1^{a}$ a $3 a$ série do Ensino Fundamental da escola Floracy Bonfim Pereira de Araújo; em pintura mural, uma das atividades posteriores às aulas de arqueologia.

contrário das nossas expectativas, de adultos: era uma simulação de escavação (previamente montada pela equipe de professores arqueólogos) - ver fig. 5.

A Semana de Arqueologia não se restringiu ao espaço das escolas, havendo, nos últimos dias, algumas apresentações de grupos de seresta, mostra de trabalho dos alunos, a outras apresentações da comunidade como as danças tradicionais da Pastorinha, Suscia, oração do Imperador e Folia. Tais eventos paralelos no seio da Semana de Arqueologia, se parecem destoar do conteúdo arqueologicamente orientado, no que tange à idéia de conscientização patrimonial, fo-
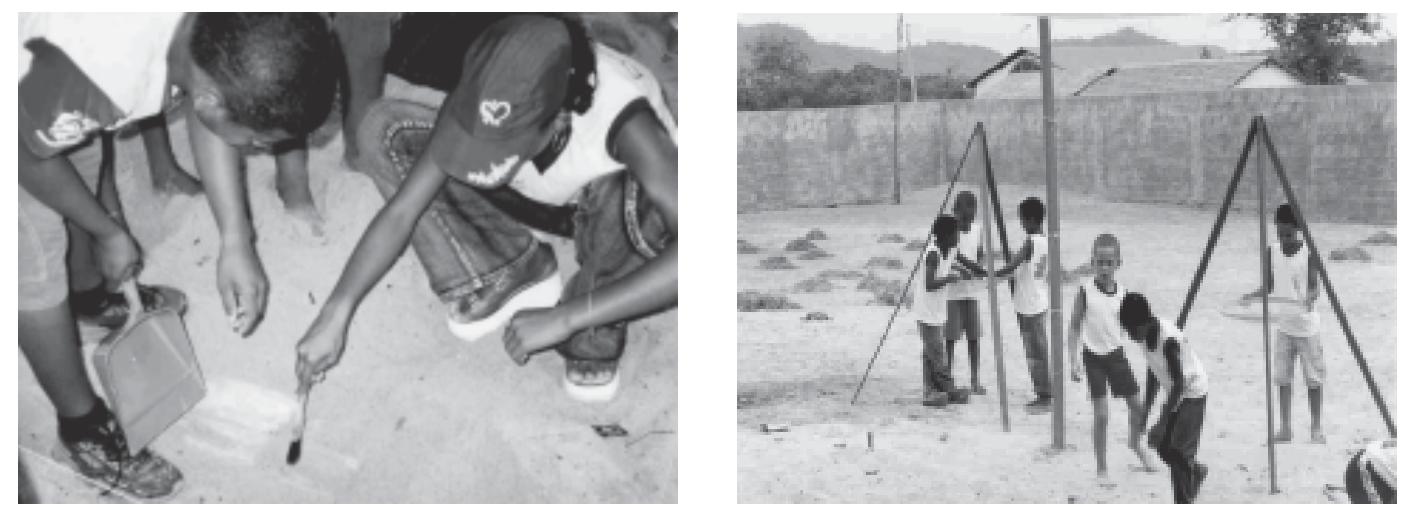

Fig. 5. "Tivemos nosso dia de arqueólogos!" (Lamyara Macedo - 6a A, Escola Virgílio de Melo Franco). A experiência da escavação: uma das atividades mais apreciadas pelos alunos. 
ram bastante positivo. Destaca-se, nesse sentido, o grande evento que findava a Semana de Arqueologia na cidade, sediado num local de grande agregação social: trata-se da Feira Coberta de Paranã, local onde ocorrem vários eventos da cidade, e há, ao seu lado, um pequeno comércio bastante freqüentado. Ali, foram expostas as atividades produzidas durante a semana pelos alunos, num evento que conclamava toda a cidade. Foi nesse local, de reconhecimento fácil e grande circulação, entre as manifestações culturais que todos bem conheciam, instalou-se a reflexão produzida sobre a cidade no tocante à arqueologia e ao patrimônio. Foi, no seio de manifestações tradicionais mescladas àquele conhecimento recentemente adquirido, que se encerrou a Semana de Arqueologia de Paranã.

\section{A idéia de parceria na Arqueologia Pública}

Há dois atores que devemos caracterizar nessa idéia de parceria, atores bem diferentes, cabe dizer, mas cuja união pode ser bastante fecunda, se efetivamente dialética, quando inseridos no quadro da Arqueologia Pública, sobretudo na dinâmica de uma pedagogia arqueológica. Os atores são os seguintes: de um lado o profissional (o arqueólogo) e do outro o que se denomina geralmente como "leigo". Há que se saber que, diferente de qualquer acepção pejorativa do termo, o leigo pode estar no plano do interlocutor altamente intelectualizado, inclusive na tradição acadêmica, ou aquele completamente distante dela: o leigo é apenas aquele que não conhece bem a Arqueologia, seus processos científicos, jargões específicos etc.

A aparente apresentação opositiva não é casual. Acreditamos que haja mesmo um distanciamento que deve ser sanado, através de uma aproximação que não seja baseada em práticas unidirecionais (o que só confirmaria tal oposição). Nesse sentido, a Arqueologia, apresentada no seio escolar, ou seja, em contornos pedagógicos, é bastante viável, e é neste ponto que a experiência em Paranã, como professores-arqueólogos, deve ser retomada.

É importante lembrar que os dois atores encontraram novidades: um, pois lhe será apresentado algo novo, que conhece pouco ou desconhece completamente; e ao outro, pois a escola elementar é um espaço diferente, com dinâmicas novas, a que o pesquisador tem que se adaptar em parte. 0 público é diverso daquele com que ele está acostumado a dialogar, e os objetivos de tal comunicação também são diversos. 0 dito professor-arqueólogo não é aquele que se relaciona cotidianamente com essa dinâmica escolar, ele aparece em situações freqüentemente de exceção, ao contrário dos professores de História, Português, Matemática etc., matérias cujos docentes não são necessariamente pesquisadores, e mesmo que sejam, eles devem seguir, pelo menos em parte, um projeto, um plano de ensino (pedagógico), discutido no seio da escola, conselho tutelar, comunidade etc. 0 professor-arqueólogo chega no contexto escolar com algo definido por ele e (ou) por uma equipe que integra, o conteúdo não é discutido no seio escolar e comunitário.

Em Paranã, o caráter de exceção característico dessa inserção do arqueólogo no seio escolar foi amplamente observado. Em primeiro lugar, a chegada de um grupo de estranhos provocou certa ansiedade na cidade, e questões como as do título deste artigo surgiam. Iniciadas as atividades, as aulas apresentadas contavam com aparelhagem de reprojeção digital e microfones - ver fig. 6; o que era bastante diferente dos recursos que as escolas possuíam. Ainda, houve certa reestruturação das salas, e em alguns casos até a remoção para outro espaço (a Feira Coberta de Paranã), que acolhia meIhor a aparelhagem e as grandes turmas de alunos.

Toda essa reorganização promovia a inserção de um pessoal (os professores-arqueólogos) e conteúdos novos nas escolas. Mas, dadas as condições climáticas (a cidade é 


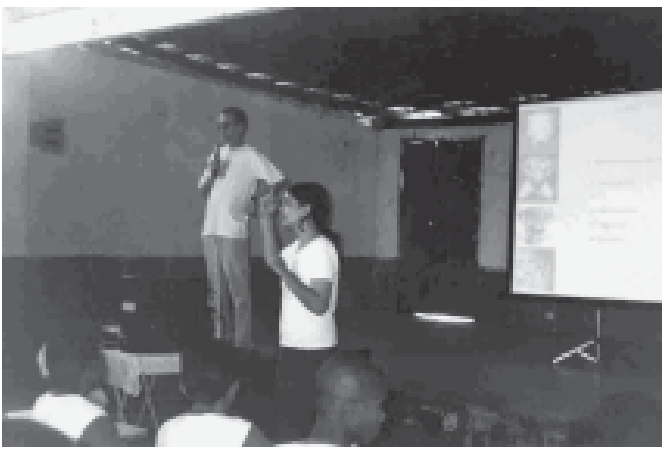

Fig. 6. Paulinho e Leilane ensinando arqueologia.

bastante quente em novembro), episodicamente a aparelhagem falhou, e uma comunicação mais próxima da dinâmica cotidiana da escola restabeleceu-se (na falta de aparelhos, restavam as lousas e gizes).

Tal esforço servia, claramente, a uma conscientização (em alguns casos até primária) sobre o patrimônio arqueológico. Entretanto, como romper as barreiras da conscientização primária (essa passo fundamental, mas inicial) e alcançar a participação no processo seletivo, muitas vezes restrito aos profissionais relacionados à Arqueologia e ao museu?

As decisões do arqueólogo, a partir de pressupostos científicos, freqüentemente propõem seleções de artefatos, construções arquiteturais etc., cuja conservação será feita. ${ }^{9}$ Há, dessa forma, uma intervenção grande no quadro das referências das coisas a serem guardadas, conservadas e lembradas. São comuns as permanências de objetos arqueológicos dentro de instituições acadêmicas como museus universitários, ou mesmo em outros casos, em museus históricos e de arte.

(9) A noção de preservação, numa discussão sobre a Arqueologia Pública que se pretenda realmente ampla, é variada. Vai desde a preservação material, até tudo 0 que ela implica ideologicamente. Preservar, nesse sentido, significa dar destaque a alguns elementos, visando sua continuidade (talvez perenidade); uma sobrevivência física, mas também no campo da memória.
O estatuto do objeto no museu é diverso daquele no contexto que foi criado e utilizado de forma primária, e mesmo do "abandono", sanado pela ação arqueológica. Distante da dinâmica do museu universitário, a própria discussão artística do século XX indicava para um debate do papel de determinados objetos num museu, e da variação de seu estatuto em contextos diferentes. Lembremos aqui da pilha de caixas de suco de tomate Campbell, criada por Andy Warhol (1969), e do miquitório (intitulado La Fontaine) assinado por Mutt (1917), heterônimo de Marcel Duchamp (ver figs. 7 e 8). Ora, seriam os mesmos se estivessem no seu local de origem (a prateleira de um supermercado ou num banheiro público qualquer?). A resposta passa, efetivamente, pela compreensão do estatuto, da constituição de uma "aura" do que está encerrado nas dependências de qualquer museu.

Escolher esses objetos "auráticos", passa, em parte, pela ação arqueológica desde seus primórdios, ou seja, já na sua entonação antiquarista, que se caracterizava, em muitos casos, por uma forte aproxi-

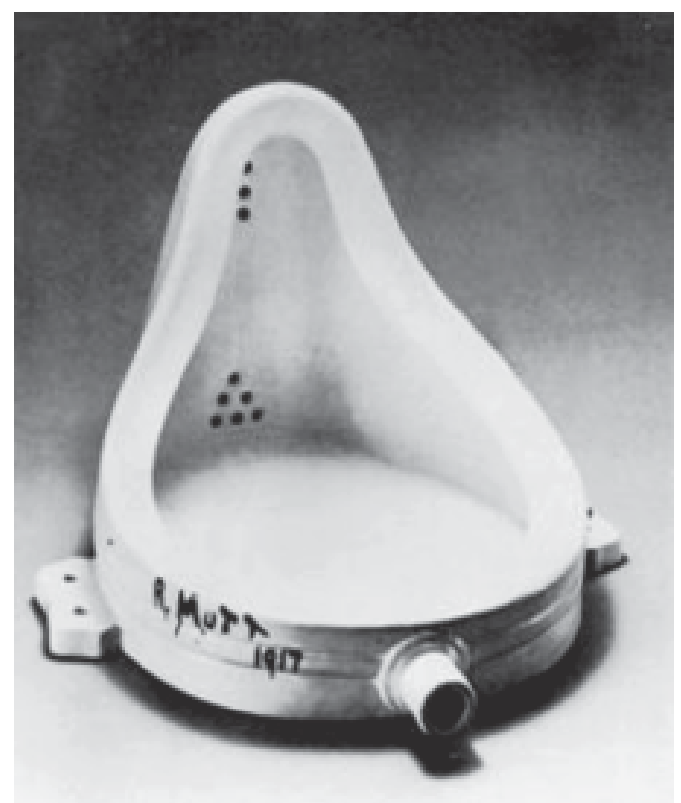

Fig. 7. A Fonte, Marcel Duchamp, 1917. 


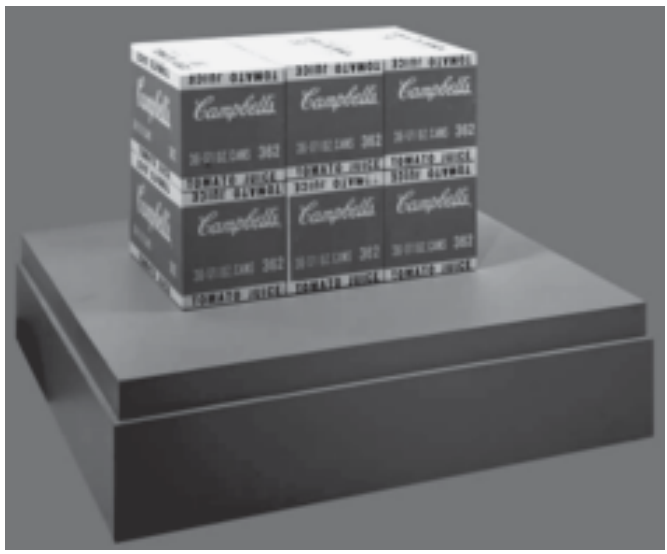

Fig. 8. Suco de tomate Campbell, Andy Warhol, 1969.

mação com o Estado, quando, desde a época moderna, este toma a empresa de preservação patrimonial para si. Tal situação deu-se freqüentemente contígua a um uso no campo da propaganda institucional estatal, como no caso da Escandinávia, Suécia, Dinamarca, desde o século XVI. Clark (1985: 57) conta algo sobre a criação de um Museu Nacional dinamarquês, que

Incorporando coleções provenientes da Kunstkammer real, e a nomeação de uma comissão régia para salvaguardar monumentos nacionais estabeleceram um firme vínculo entre o sentimento de identidade nacional e as relíquias do passado dinamarquês.

Assim, foi no seio da ação acadêmi$c a$, freqüentemente endossada pela estatal, que se escolheram e preservaram as coisas que devem ser rememoradas. A idéia de parceria, numa acepção mais ampla; ou seja, desobjetivando o outro (no caso, o público leigo) parece propor uma mudança nessa situação. Uma pedagogia arqueológica serviria para algo muito além de ensinar 0 que é importante arqueologicamente falando (o passo inicial), mas de munir o leigo para uma participação efetiva nessas escolhas.

A ação conscientizadora não se deve pautar numa situação iluminista de fluxo unidirecional de conhecimento; mas ela pode ser bastante importante quando se pensa em integrar o público leigo nas escolhas finais do processo de preservação patrimonial. Nesse sentido, as práticas de Arqueologia Pública, sobretudo as de entonação pedagógica, têm papel essencial na formação (e não condicionamento) do público leigo. 0 reconhecimento dos materiais, da função do arqueólogo, e do estatuto que esses devem ocupar no seio de sua comunidade devem ser escolhidos, discutidos e construídos no seio de um diálogo. Diálogo, no sentido mais amplo da palavra, ou seja, uma relação dialética, onde há certas interdependências. Os papéis são claramente diferentes, mas relativos.

A prática arqueológica propõe diálogos com populações locais, antes mesmo de qualquer proposta de Arqueologia Pública. Destaca-se, nesse quadro, uma linha que vê no outro, no leigo, um parceiro relativamente importante na pesquisa arqueológica. Alguns manuais de Arqueologia indicam a importância do diálogo com populações locais, que geralmente guardam na memória histórias, e mesmo objetos materiais encontrados ao longo de sua existência. Conversar com eles, então, mostra-se em alguns casos indispensável. ${ }^{10}$ Entretanto, essa prática está longe de uma ação arqueológica pública, dado que o relato do outro é usado de forma quase puramente instrumental, e não é previsto algum retorno posterior.

Por fim, é devido dizer que uma Arqueologia que proponha um verdadeiro diálogo com o outro lado dos muros da academia, quando inserida nos processos educativos, mesmo em caráter de exceção, deve estar atenta às questões feitas pelo outro, se visa

(10) "A informação oral torna-se muito útil, em geral, nos casos em que o arqueólogo está estudando um sítio que foi ocupado em tempos ainda presentes na memória de testemunhas, ou nos casos em que 0 arqueólogo deseja conhecer a história do sítio após seu uso pelo povo que originalmente o construiu". (Orser J r, 1992: 45) 
tê-lo como parceiro. As perguntas do título aparentemente apresentam respostas simples, as quais o arqueólogo tem bastante desenvoltura para responder. Porém, visando reconhecer o outro como parceiro, essas questões devem sempre ser pensadas de forma relativa, e não com uma objetividade peculiar do discurso cientificamente baseado. 0 arqueólogo, suas interpretações, os materiais com que trabalha, tudo isso está inserido num universo amplo de significados, por mais que durante muito tempo tenha-se optado por ações restritivas.

A Arqueologia é uma área que lida freqüentemente com questões sobre o passado, e o debate patrimonial insere ações sobre o presente. ${ }^{11}$ É necessário deixar claro que não é apenas a discussão patrimonial que aproxima a Arqueologia das questões do nosso presente. A reflexão teórica sobre a disciplina e sobre sua própria história indica que a reflexão arqueológica sobre a cultura material produzida no passado são interpretadas a partir de abordagens teóricas e problemas freqüentemente relacionados ao universo do pesquisador.

\section{AGRADECIMENTOS}

Agradecemos ao professor doutor Pedro P. A. Funari, pelo interesse, gentil convite para publicação e sugestões bastante apropriadas; bem como à professora doutora Erika M. Robrahn-González, pela disposição e interesse sobre nossas atividades, desde a Semana de Arqueologia em Paranã, até a disponibilização de informações importantes para a confecção deste artigo. Agradecemos também as empresas e instituições envolvidas na organização e execução da Semana de Arqueologia em Paranã (Documento Antropologia e Arqueologia Ltda., Enerpeixe, Núcleo de Estudos Estratégicos - Arqueologia Pública/Unicamp e Fundação Cultural de Jacarehy); e todos os integrantes da equipe de professores-arqueólogos (Wagner, Paulinho, Vinícius, Kelly, Silvana e Patrícia). Por fim, cabem agradecimentos ao CNPq, cujo incentivo financeiro é responsável pela permanência das atividades acadêmicas de um dos autores deste artigo. As idéias aqui expostas são de inteira responsabilidade dos autores.
(11) É necessário deixar claro que não é apenas a discussão patrimonial que aproxima a Arqueologia das questões do nosso presente. A reflexão teórica sobre a disciplina e sobre sua própria história indica que a reflexão arqueológica sobre a cultura material produzida no passado são interpretadas a partir de abordagens teóricas e problemas freqüentemente relacionados ao universo do pesquisador. 
Abstract: The aim of this article is to comment about the partnership notion into the Public Archaeology debate, specifically in the classroom dynamic. The comprehension about the archaeology role in this context will be based on the authors' experience as archaeology teachers during the Semana de Arqueologia de Paranã - TO (Paranã Archaeology Week TO), a hands-on related to archaeological research activities in an environmental impact zone, where a dam is about to be built.

Keywords: Identity, Public Archaeology, Heritage Education, Heritage, Partnership

\section{Bibliografia}

ALMEIDA, P. A.

2005 Arqueologia em Conceição dos Ouros MG. Pouso Alegre: Gráfica e Editora Amaral.

BESSEGATO, M. L.

2004 O patrimônio em sala de aula: fragmentos de aços educativos. 2a edição, Porto Alegre: Evangraf.

BESSEGATO, M. L. \& MILDER, S. E. S.

$2005 \mathrm{OH}$ ! A sala de aula como um local de interjeição as questões patrimoniais. CRUZ, A. R. \& OOSTERBEEK, L. Arkeos. Perspectivas em diálogo. n. 15. 2005: 81-94.

BRAUDEL, $F$.

1986 A longa duração. In: História e ciências sociais. Editorial Presença, 5a ed., : 7-39.

CALDEIRA, C. C.

2006 Conservação preventiva: histórico. Revista $C P C$, v. 1, n. 1. (consultado no site http://www.usp.br/cpc/v1/php/ wf07_revista_capa.php, em 20 de janeiro de 2006).

CLARK, G.

1985 Identidade do homem. Uma exploração arqueológica. Trad. Álvaro Cabral. Rio de Janeiro: Jorge Zahar Editor.
FUNARI, P. P. A.

2005 Apresentação. In: ALMEIDA, P. A. 2005 Arqueologia em Conceição dos Ouros MG. Pouso Alegre: Gráfica e Editora Amaral: 5-8.

FUNARI, P. P. A; OLIVEIRA, N. V. \& TAMAMINI, E.

2005 Arqueologia para o público leigo no Brasil: três experiências. In: FUNARI, P. P. A.; ORSER JR, C. E. \& SCHIAVETTO, S. N. de O. (orgs.) Identidades, discurso e poder: estudos da Arqueologia contemporânea. São Paulo: Annablume, Fapesp 2005: 105-116.

HOBSBAWN, E.

1997 A invenção das tradições. In: HOBSBAWN, E \& RANGER, T. (orgs.) A invenção das tradições. Rio de Janeiro: Paz e Terra. 1997: 9-24.

OOSTERBEEK, L.

2005 Arqueologia pré-histórica: entre a cultura material e o patrimônio intengível. CRUZ, A. R. \& OOSTERBEeK, L. Arkeos. Perspectivas em diálogo. n. 15. 2005: 95-113.

ORSER JR, C. E.

1992 Introdução à Arqueologia histórica. Trad. de P. P. A. Funari. Belo Horizonte: Oficina de Livros. 